\title{
Study on the dilemma and Countermeasures of rural environmental pollution control under the background of Rural Revitalization Strategy
}

\author{
Xiaojuan $\operatorname{Han}^{1}$ \\ ${ }^{1}$ Shangdong women's university, No.2399 Daxue Road, Changqing District, Jinan City, Shandong Province, China
}

\begin{abstract}
Environmental pollution has been the focus of attention in recent years. The 19th National Congress of the Communist Party of China put forward the strategy of rural revitalization, which pointed out that we should adhere to the harmonious coexistence of man and nature. Under the background of Rural Revitalization Strategy, we should improve the rural living environment and accelerate the transformation and upgrading of agriculture. We should establish and improve the rural environmental governance system, realize the construction of ecological civilization, and adhere to the implementation of green development and innovative development. Based on the background of Rural Revitalization Strategy, taking YZ town as an example, this paper analyzes the difficulties of rural environmental pollution control, such as weak awareness of environmental pollution control, low efficiency of environmental protection funds, and puts forward corresponding countermeasures.
\end{abstract}

\section{Research background and significance}

\subsection{Research background}

In recent years, environmental problems have attracted the attention of all sectors of society. In view of the problem of environmental pollution, the government has issued a series of laws and regulations in order to realize the construction of ecological civilization. We should adhere to the implementation of green development and build a beautiful China. The 19th National Congress of the Communist Party of China put forward the strategy of rural revitalization, which pointed out that we should adhere to the three steps of Rural Revitalization. At present, the implementation of Rural Revitalization Strategy has achieved certain results, but it still needs to continue to work hard. In order to build ecological and livable villages proposed in the strategic plan of rural revitalization, we should control the rural environmental pollution, adhere to the harmonious coexistence of human and nature, and take the road of rural green development.

\subsection{Research significance}

\subsubsection{Theoretical significance}

Under the background of Rural Revitalization Strategy, we should do a good job in rural human settlements, establish and improve the rural environmental pollution control system, and adhere to the harmonious coexistence of human and nature. Rural environmental pollution control work is complex, we should plan scientifically and implement it effectively. Taking YZ Town, Jining City, Shandong Province as an example, this paper investigates the current situation of rural environmental pollution control, analyzes the existing problems of rural environmental pollution control, and puts forward targeted solutions on this basis. These studies are expected to play a complementary role in the theoretical study of environmental pollution control.

\subsubsection{Practical significance}

The quality of rural environment is not only related to the quality of life of rural residents, but also affects the development of rural economy. Based on the background of Rural Revitalization Strategy, this paper analyzes the problems of rural environmental pollution, and enhances the environmental awareness of rural residents. These studies hope to play a certain reference role in the construction of ecological livable villages.

\section{The current situation of rural environmental pollution under the background of Rural Revitalization Strategy}

In this paper, Jining City, Shandong Province, YZ Town, as an example, we conduct field research to understand the rural environmental pollution under the strategy of Rural 
Revitalization. Since the implementation of the Rural Revitalization Strategy, YZ town has taken a series of measures, such as the government of $\mathrm{YZ}$ town to encourage villagers to establish ecological agricultural parks, introduce strawberry industry, increase aquaculture, etc., and increase the economic sources of villagers. In recent years, great changes have taken place in YZ Town, and the implementation of Rural Revitalization Strategy has achieved obvious results. But there are also some problems. For example, employees in YZ town have low educational background, as shown in Figure 1.

Proportion of employees' educational background in YZ Enterprises

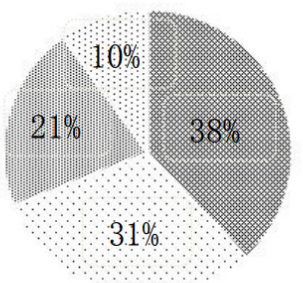

primary school . junior middle school it high school . University and above

Fig1. Proportion of employees' educational background in YZ town.

Most enterprises in $\mathrm{YZ}$ town are garment production and processing enterprises. According to the survey on the educational background of employees in YZ Town, we can see that nearly $70 \%$ of employees have junior high school or primary school education and only $10 \%$ of them have university degree or above. These facts tell us that the educational level of employees in $\mathrm{YZ}$ town is relatively low and the knowledge of environmental protection is relatively limited.

In the process of toilet transformation, some villagers didn't actively cooperate. Through the investigation of toilet renovation in YM village of YZ Town, we can get Figure 2. As can be seen from Figure 2, about $25 \%$ of the villagers didn't cooperate with the renovation of the toilet and couldn't understand the event; about $57 \%$ of the villagers actively cooperated with the renovation of the toilet; and about $23 \%$ of the villagers cooperated with the renovation of the toilet.

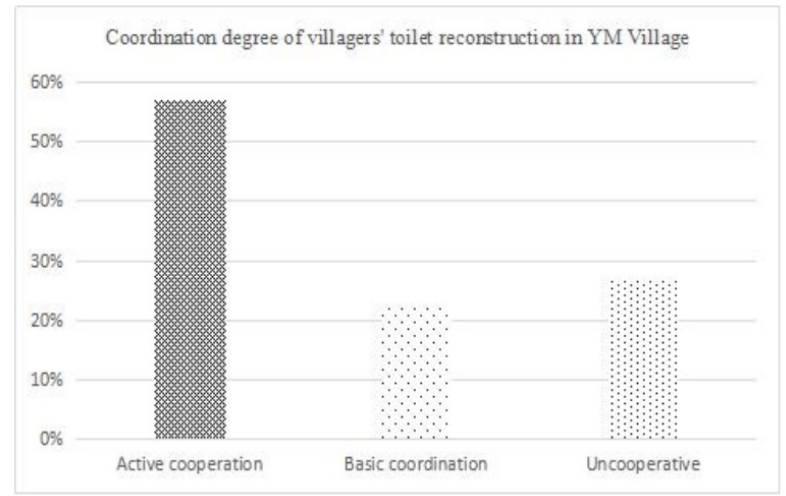

Fig2. Coordination degree of villagers' toilet reconstruction in YM village, $\mathrm{YZ}$ town

\section{The dilemma of rural environmental pollution control under the background of Rural Revitalization Strategy}

Based on the investigation of the environmental situation of YZ Town, combined with the current situation of rural environmental pollution control in YZ Town, this paper analyzes the existing problems of rural environmental pollution control in YZ town from the aspects of government, enterprises and the masses.

\subsection{The Government level}

\subsubsection{The grass roots environmental protection governance mechanism isn't perfect}

The grass-roots government departments are the front-line departments to implement the relevant national environmental protection policies. They have a lot of contact with enterprises, the masses and the media. However, the grass-roots environmental protection governance mechanism isn't perfect. On the one hand, the government lacks communication with enterprises and the masses, and has not established a perfect communication mechanism. Enterprises, the masses and other participants aren't aware of environmental protection, and they can't attract enough attention. On the other hand, the environmental protection facilities of the government are insufficient.The government of YZ town is lack of hightech monitoring equipment, which can't accurately monitor and control environmental pollution in advance. In addition, the grass-roots environmental protection supervision personnel are limited, considering the complexity of environmental protection issues, grassroots law enforcement departments are often unable to do their best in law enforcement and supervision. They tend to reconcile the situation of rural environmental pollution, and it is difficult to solve environmental protection problems from the source.

\subsubsection{The information of environmental pollution control isn't timely grasped}

The source of rural environmental pollution is extensive, the means are various, and the randomness is strong. According to the characteristics of rural environmental pollution, YZ town government has set up a special patrol team to patrol and inspect the rural environmental pollution. However, the timeliness of the government and other parts of the understanding of environmental pollution information is still poor. They often grasp the information after the occurrence of environmental pollution, unable to do a good job in precontrol. For example, for the behavior of villagers burning straw, the government usually finds a lot of smoke and then stops extinguishing the fire. It is difficult to find the perpetrators of the burning behavior. 


\subsubsection{The assessment and incentive mechanism isn't perfect}

For example, under the guidance of the grass-roots government departments, YZ town has basically completed the transformation of rural toilets. However, the evaluation and incentive mechanism of environmental pollution control work isn't perfect, which leads to the low enthusiasm of relevant participants and limited treatment effect. Environmental protection work involves all aspects of life, the evaluation incentive mechanism isn't perfect, the evaluation content guidance isn't clear, which can not timely grasp the plight of environmental governance, resulting in low efficiency of environmental pollution control.

\subsubsection{Lack of long-term mechanism for environmental governance}

$\mathrm{YZ}$ town is equipped with garbage collection, clothing collection and other facilities, and set up a special garbage disposal place. However, rural residents still have the phenomenon of randomly discarding garbage and burning straw at will, and the utilization efficiency of infrastructure is low. At the same time, the investment of environmental pollution control facilities is often sufficient in the early stage, and the utilization rate is low after the investment, which will lead to the phenomenon of idle and waste in the later stage. When the facilities are damaged, they don't maintain or manage them.

\subsection{The Enterprise level}

\subsubsection{Lack of legal concept of environmental protection}

The enterprises in $\mathrm{YZ}$ town are mainly garment production enterprises, and the environmental pollution mainly involves dust pollution. Most of the employees in YZ town are residents of YZ Town, which lacks the concept of legal management of environmental protection. On the one hand, the educational level of employees in $\mathrm{YZ}$ town is generally low, about $60 \%$ of them are junior high school graduates. Their environmental awareness is weak and they can't pay enough attention to environmental protection and environmental governance. On the other hand, their learning effect on environmental protection policy isn't ideal.

\subsubsection{Low level of industrial structure and insufficient participation in corporate governance}

As one of the main bodies of environmental pollution control, enterprises play an important role in environmental pollution control. Most enterprises in $\mathrm{YZ}$ town are small and micro enterprises. According to the statistical data, we can see that most enterprises have not installed relevant sewage facilities. Due to the limited funds, enterprises pay more attention to how to reduce production costs and improve economic benefits, but less investment in environmental protection. The government have brought many preferential policies to enterprises through tax reduction and fee reduction. However, in order to pursue economic benefits, enterprises ignore environmental protection and governance, and lack of intensity to participate in environmental pollution control.

\subsubsection{Low utilization rate of funds}

YZ town enterprise environmental pollution control fund source is mainly from the government, the enterprise investment is less. Based on the perspective of pursuing economic interests, the funds invested by the government aren't fully and effectively used in the environmental pollution control of enterprises, and the utilization efficiency of funds is low.

\subsection{The Mass level}

\subsubsection{Lack of awareness of environmental protection and low awareness of participation}

The villagers are lack of understanding of environmental pollution control and can't fully realize the importance of environmental pollution control.Most residents think that environmental protection has nothing to do with themselves. Through investigation, we found that about $40 \%$ of rural residents do not think that burning straw will cause serious impact on environmental pollution. About $20 \%$ of the rural residents do not support the renovation of toilets in the process of toilet renovation by YZ town government. These villagers believe that traditional toilets will not cause serious pollution to the environment. Rural residents are lack of awareness of environmental pollution control, and the enthusiasm and initiative of rural residents to participate in environmental governance are low.

\subsubsection{Decrease of rural resident population}

The rural living environment involves many aspects. The number of villagers in $\mathrm{YZ}$ town who go out to work and study is increasing, and the rural permanent population is decreasing, and most of them are the elderly, women and children, which will cause a lot of idle and waste of infrastructure. In terms of environmental pollution control, the government has invested funds in the construction of infrastructure. With the loss of young villagers in YZ Town, the problems of idle infrastructure and low utilization efficiency will affect the implementation of Rural Revitalization Strategy to a certain extent.

\subsubsection{Insufficient third party or public supervision}

The environmental atmosphere of villages and towns depends on the living habits of villagers. Influenced by traditional ideas, most villagers can't attach importance to environmental protection and environmental pollution control. Rural areas lack the supervision of third parties or public media, such as villagers burning garbage. The supervision of the third party or the public media isn't enough, and the villagers are lack of consciousness. 


\section{Countermeasures of rural environmental pollution control under the background of Rural Revitalization Strategy}

\subsection{The Government level}

\subsubsection{Establish and improve the grass-roots environmental protection mechanism and strengthen supervision}

On the one hand, the government can establish a sound communication mechanism to communicate with enterprises, the masses and the public in a timely manner. Through communication, the government can obtain sufficient environmental information to deal with or prevent environmental pollution incidents in time. On the other hand, the government can increase the investment of governance funds and provide sufficient financial guarantee. For example, the government can optimize the allocation of infrastructure, purchase high-tech environmental protection equipment, establish environmental protection big data platform, and improve work efficiency. Third, the government should increase the proportion of environmental supervision personnel, strengthen the government's understanding of environmental pollution, and achieve prevention and control in advance.

\subsubsection{Timely grasp information and play a leading role of the government}

The government should understand the rural environmental conditions through various channels and ways. For example, the government can build an environmental protection big data platform to timely understand the latest environmental pollution situation, actively mobilize multiple parties to participate in environmental pollution control and protection work, and play the leading role of the government on the basis of equal communication and exchange. The government should establish and improve the environmental protection accountability system and establish an effective information sharing platform.

\subsubsection{Establish and improve the assessment and incentive mechanism of environmental protection governance}

The government should establish and improve the assessment mechanism of environmental protection governance in combination with the specific situation of villages and towns. The government should set up the content of the assessment and incentive mechanism, and give appropriate rewards and punishments according to the specific situation of environmental pollution control in villages and towns and the environmental protection supervision. Enterprises or villages with better environmental pollution control should be given appropriate rewards to encourage them to continue to actively carry out environmental protection work; for enterprises or villages and towns with poor environmental pollution control, the government should give appropriate punishment and warn them to conscientiously abide by and implement relevant environmental protection policies and regulations.

\subsubsection{Establish long-term environmental governance mechanism}

The government should increase investment in high technology in environmental pollution control and environmental protection. In the traditional supervision mode, the government supervision is often based on human resources. With the development of information technology, the government can strengthen the supervision and management of environmental conditions through database and other information platforms or monitoring facilities, establish a long-term environmental pollution control system, and timely maintain and protect infrastructure. At the same time, the government should make clear the responsibilities of the main participants in environmental protection work, so as to achieve the unity of rights and responsibilities and long-term effectiveness.

\subsection{The Enterprise level}

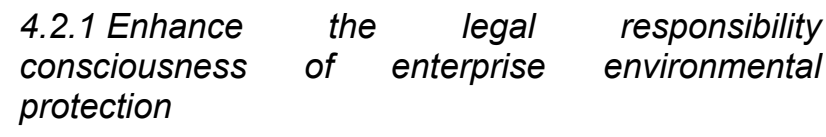

Under the background of Rural Revitalization Strategy, we should improve rural living environment and establish ecological livable villages. The most important thing is that we should improve the legal awareness of environmental protection. On the one hand, enterprises should improve the educational background of employees and strengthen the environmental awareness of enterprise management and employees. On the other hand, enterprises can regularly invite environmental experts to train their employees, strengthen the study of environmental pollution control knowledge, and deepen the understanding of relevant national environmental protection policies. In addition, enterprises can strengthen the environmental knowledge education of employees in the corporate culture.

\subsubsection{Adjust industrial structure and increase participation in environmental protection}

First, enterprises can upgrade and transform traditional industries. For example, we can develop new processes, use new technologies to produce products, and control environmental pollution from the source by means of information technology such as big data. Secondly, enterprises should develop modern agriculture, attract college students to work in their hometown and village, and increase the participation of each subject in environmental protection.Third, enterprises should establish large-scale green agricultural production base 
and strengthen the upgrading and transformation of industrial structure. Enterprises should introduce professional talents and improve environmental protection technology. For example, enterprises can select college students village officials, seek technical support for environmental protection planning, combine internal and external, train local talents and increase environmental protection participation.

\subsubsection{Improve the utilization efficiency of environmental protection funds}

The construction of ecological livable villages is inseparable from the financial guarantee. Under the current policy, the government have given a lot of special funds for environmental protection. Enterprises should use the special funds for special purposes and use them in the most appropriate places to improve the efficiency of funds. We should give full play to the proper use of government special funds and stimulate the enthusiasm of enterprises to participate in environmental protection.

\subsection{The Mass level}

\subsubsection{Strengthen villagers' awareness of environmental protection and enhance their awareness of environmental protection participation}

Under the background of rural strategy, as one of the main participants in environmental protection, we must strengthen villagers' awareness of environmental protection and enhance their awareness of environmental protection participation. First, we should strengthen the publicity and education of villagers to make them realize the importance of environmental protection and environmental pollution control. Second, we should pay attention to multi-channel and multi-way publicity, interpret environmental protection policies and strengthen environmental protection publicity. Third, we should encourage villagers to actively participate in environmental and economic pollution control work, protect the environment, and establish ecological and livable villages.

\subsubsection{Attracting college students to return home}

The grass-roots departments of villages and towns can set up corresponding policies to attract talents, attract rural college students to return home, and strengthen the work of rural environmental pollution control. The grass-roots departments should support the young people to return home, increase the permanent rural population and improve the efficiency of environmental protection infrastructure. Villagers should actively participate in the implementation of Rural Revitalization Strategy and strive to implement various policies and regulations.

\subsubsection{Enhance the supervision of the third party or the public}

Rural grass-roots departments should build informationbased big data platform to improve the supervision of the third party or the public. Villagers timely understand the relevant information of environmental pollution control and actively participate in environmental pollution control and environmental protection work. Through the supervision of the third party or the public, we can strengthen the villagers' awareness of environmental protection and highlight the main role of the villagers. Village cadres should strengthen the sense of leadership, lead villagers to correctly understand the importance of environmental protection, make villagers actively participate in environmental pollution control, and make villagers make certain contributions in the process of implementing the strategy of Rural Revitalization.

\section{References}

1. Yucan Huo,Study on the dilemma and solution path of feed enterprises supporting rural ecological environment governance under the background of Rural Revitalization ,China feed, 15 (2020)

2. Wenbo Qu, Shuling Li. Public participation in environmental pollution control in China: An Empirical Study Based on dynamic spatial panel model,Journal of Beijing University of Technology (SOCIAL SCIENCE EDITION), 22 (2020)

3. Chun Jin. Research on the impact of fiscal decentralization on environmental pollution -- Based on the threshold effect of policy environment,Friends of accounting, 06 (2020)

4. Zhen Cao, Zhanhao Gu,Discussion on rural ecological livable construction under the background of Rural Revitalization -- Based on the investigation of Zhejiang Province, Chinese Youth Social Sciences, 38(2019)

5. Jixi Gao, Qinfang Sun, Zhu Lin, Implementing Rural Revitalization Strategy and promoting rural ecological civilization construction, Environmental protection, 46(2018)

6. Maoyou Deng,Ecological environment problems of rural tourism in China and countermeasures, Agricultural economy, 04 (2017) 